\title{
A hora da biografia
}

$\mathrm{O}$ gênero biografia converteu-se, nos últimos anos, em um dos centros de interesse acadêmico dos cursos de Humanidades. Sua natureza interdisciplinar, entre a história e a literatura, requer o concurso de outras disciplinas (antropologia, sociologia, psicologia, psicanálise...) e de reflexões teóricas que permitam satisfazer as exigências analíticas e de conhecimento próprias do trabalho intelectual.

Vivemos a idade de ouro da biografia, ao menos no que diz respeito ao mundo ocidental. Isso sustenta Nigel Hamilton na abertura de seu How to do Biography (Harvard University Press, 2008). O interesse pelas vidas reais se acha presente em todos os meios de comunicação (cinema, televisão, imprensa, internet), monopoliza as novidades editoriais e por fim está entrando no mundo acadêmico como uma disciplina que, incrustada entre a história e a criação literária, facilita a interpretação da vida humana individual, passada ou presente. No entanto, o atraso ou a lentidão com que se está produzindo essa incorporação, ao menos no contexto iberoamericano, torna-se um pouco decepcionante, dada à imensa contribuição que a escritura biográfica tem proporcionado ao mundo do conhecimento e da cultura. É por isso que Letras de Hoje buscou dedicar um número monográfico sobre o gênero, reunindo um grupo de estudiosos em tal campo de estudo, para proporcionar diferentes perspectivas de aproximação e de análise sobre o tema da biografia.

Frente à autobiografía, que tem concentrado o debate literário mais importante dos últimos vinte anos - mencionam-se dois livros teóricos fundacionais: a publicação de Le pacte autobiographique de Philippe Lejeune, en 1975, y "Autobiography as De-Facement" de Paul de Man, publicado originalmente em Modern Language Notes (1979) e reimpresso en The Rhetoric of Romanticism (1984). Pois bem, frente à emergência teórica da autobiografía como escritura que propõe problemas medulares em relação à verdade, a criação da personagem ou a autoreferencialidade, a biografia é uma escritura que apenas mereceu interesse para a teoria literária, e muito pouco para a historiografia, em que pese manejar conceitos e ferramentas fundamentais para sua hermenêutica e de grande interesse epistemológico, como o uso que faz das fontes, a seleção das fontes, o ponto de vista do biógrafo, a relação biógrafobiografado. $\mathrm{O}$ fato mais elementar de toda a biografia, o conhecimento da personagem a ser biografada, abre por si uma problemática enorme, pois a tarefa de investigar, que pode ser um trabalho mais ou menos opcional em outras disciplinas e escrituras, é o coração da biografia, o que verdadeiramente distingue a prática das chamadas lifes-writing da escritura de ficção.

A biografia, porém, requer un humus adequado para se desenvolver. Requer libertade e um espírito democrático que aceite a possibilidade de revisar a singularidade de uma trajetória humana sem condicionamentos espúreos que determinem seus objetivos. Sem falsidades e imposturas. Essa revisão do passado é imprescindível nas Humanidades, nossa razão de ser como disciplina. Uma sociedade na qual não se podem escrever biografías é quase impensável, ao menos no lado ocidental e, apesar disso, não ensinamos o estudo e a composição da biografia na educação universitária. Até recentemente, o estudo das biografías era completamente ignorado e não fazia parte dos planos de estudo, das bibliografías e dos trabalhos acadêmicos. Isso torna muito difícil avaliar uma obra, uma investigação inédita de outras que não o são. Tem sido tão escassa a teoria gerada pela prática da biografia que sequer dispomos de um cânone, de um consenso sobre os livros que marcaram o avanço do gênero. Por tudo isso, a necessidade de impulsionar os estudos biográficos justifica a publicação deste número monográfico de Letras de Hoje.

Este número colabora, de certa forma, para preencher o vazio ainda existente sobre a teoría e práxis da biografia, especialmente na seção Ensaios, base do dossiê sobre o tema. Essa seção está constituída por um conjunto de textos produzidos por autores integrados a diferentes instituições de ensino da Europa, especialmente da Espanha, e das Américas, que, distanciados pela geografia, revelam que mantêm interesses comuns em suas investigações. Geograficamente, da Espanha, locus de estudo mais atento e dedicado ao tema da biografia, 
especialmente através da Unidad de Estudios Biográficos, da Universidade de Barcelona, coordenado por Anna Caballé, chegam dois estudos: um, de autoria da própria Anna Caballé e outro escrito por Jordi Gracia. Também da Espanha, da Universidade de Cantábria, chegam mais dois textos: o de Rafael Andugar Sousa e, com prazer, contamos com o texto de María Jesús González, da Universidade de Cantábria.

Da América do Sul, especialmente da Universidade de La República, no Uruguay, dois autores inscrevem-se no rol de estudiosos da biografia: Pablo Rocca e Juan Carlos Albarado. Da outra ponta das Américas, agora da York University, agradecemos a contribuição de Adrian Schubert. Há de se assinalar, com satisfação, que os estudiosos do Brasil, país que constitui um campo aberto para a escrita de biografías, mas que tão pouco explora esse filão nos estudos literários, também marcam sua presença neste número com quatro artigos, provenientes de diferentes centros de estudo: Cândida de Oliveira e Tânia Regina Oliveira Ramos, da Universidade Federal de Santa Catarina; Everton Barbosa Correia, da Universidade do Estado do Rio de Janeiro; Marilene Weinhardt, da Universidade Federal do Paraná; Fábio Varela Nascimento, da Pontifícia Universidade Católica do Rio Grande do Sul.

O espectro de tópicos abordados por esses estudiosos, aos quais agradecemos por sua colaboração, localizados em diferentes pontos das Américas e da Espanha, em particular, é interessante e significativo para o conhecimento do estado atual da arte no que se refere à escrita e à práxis da biografia. Anna Caballé, teórica do assunto e ela própria autora de varias biografías, em "Los horizontes epistemológicos de la biografía", incide sobre uma questão que move suas formulações teóricas sobre a escrita de biografías, ou seja, o grau de objetividade do biógrafo sobre a matéria biografada. Alargando a discussão, recai sobre a evolução da biografia na Espanha, tema que pesquisa há alguns anos e sobre os quais têm aportado contribuições originais. Nesse mesmo campo da teoría da biografia, Rafael Andugar de Sousa propõe criar um novo gênero literário a partir da leitura de diferentes obras literárias, no artigo "Breves biografías ficticias. Posibilidade de un novo género literariolecorial". Jordi Gracia, biógrafo de Cervantes, em "Imaginación moral y biografía" centra sua discussão no tópico da imaginação moral como instrumento para recriar a complexidade interior dos sujeitos biografados.

María Jesús González, biógrafa aplaudida do historiador Raymond Carr, em "God sabe the Queen. Consideraciones en torno a la biografía en Gran Bretaña", aporta importantes considerações sobre o gênero biográfico na Grã Bretanha, país que se converteu em referência internacional nesse campo de estudos.
Segundo essa autora, a biografia inglesa tomou outros rumos a partir do momento em que os biógrafos ingleses transcenderam suas fronteiras e passaram a tratar das biografías de personagens de outras nacionalidades. As reflexões presentes nesse estudo remetem não só à história do gênero na Grã Bretanha, mas também aos problemas enfrentados pelos biógrafos em suas relações com novos círculos culturais de investigação biográfica.

De Toronto, Adrian Schubert explora os modos como os historiadores têm pensado a biografia como um gênero de escrita sobre o passado, em seu artigo "What do histrorians really think about biography?" Segundo sua análise, o modo como os historiadores trataram a biografia, foi responsável por uma mudança de compreensão do gênero, nos últimos cinquenta anos. Para discutir sua proposta, traz à baila a biografia do militar e político español, Baldomero Espartero (1793-1879).

Outro bloco, centrado fundamentalmente na práxis da biografia, ou seja, em estudos que se voltam a examinar textos de caráter biográfico ou mesmo biografías de personagens ilustres ou periféricas, reúne o maior conjunto de artigos. Pablo Rocca traz à luz, em "Vida y milagros de Orsini Bertani (una semblanza: que haceres de la cultura letrada del Novecientos)", uma figura notável da história do Uruguai - Orsini Bertani um homem que circulou entre papeis e livros, mas cuja origem remonta às atividades como anarquista em seu país natal, a Itália, até chegar à capital uruguaia, onde se tornou um empresário cultural, cujo papel repercute para a formação letrada do país. Outra personalidade desse mesmo ambiente é estudado por Juan Carlos Albarado, em "Tabaré Etcheverry, un breve cantar". Trata-se de um cantor nacional que revolucionou a música no Uruguai e que, para além de questões da estética musical, envolve também questões políticas, responsáveis pela criação de uma lenda negra sobre esse cantor e compositor.

Do espaço brasileiro, as contribuições são igualmente variadas e incidem sobre a prárica da biografia com suas articulações com as novas mídias, a história e cultura, ou seja, apresentam-se os problemas vinculados a sua referencialidade, o impacto do feminismo na evolução do gênero e modelos fundacionais para a biografia contemporânea. Em "A produção de subjetividades no romance e na entrevista midiática: rastros do autobiográfico e da escrita feminista de Maria Valéria Rezende", Cândida de Oliveira e Tânia Regina Oliveira Ramos analisam a produção de subjetividades na literatura brasileira contemporânea, focando a construção da biografia de Maria Valéria Rezende, através da obra ficcional dessa escritora e de recursos midiáticos. Marilene Weinhardt toma uma figura da história brasileira, a rica e inteligente Eufrásia Teixeira Leite, descendente da aristocracia 
nacional, mulher independente, que manteve uma relação amorosa com o político abolicionista Joaquim Nabuco, centrando sua análise em dois romances que tomam essa figura feminina como personagem. Em "Eufrásia Teixeira Leite: personagem biográfica romanceada", associa romance e biografia para discutir a ficção a partir dos dados biográficos. Ainda do Brasil, o estudo de Fábio Varela Nascimento ocupa-se de uma personalidade singular do Rio Grande do Sul, o médico e escritor Cyro Martins, para recuperar os anos de sua formação, em "A tentativa biográfica: o desafio de escrever parte da vida de Cyro Martins", objeto de sua tese de Doutorado, recentemente apresentada na Pontifícia Universidade Católica do Rio Grande do Sul. Fechando esse bloco, Everton Barbosa Correia, em "Dicção individual e intervenção pública em "Três sonetos positivos", de Joaquim Cardoso", propõe que o soneto seria o locus de manifestação de uma voz singular, pouco considerada pela historiografía literária brasileira.
A Seção Livre abre suas páginas para acolher o estudo de Ana Fernandes e João Queiroz, tinitulado "O altersense do haicai", assim como a reflexão de Luciana Abreu Jardim, "Deslocamentos do imperativo visual em recortes do feminismo".

Para terminar, resta às organizadoras deste volume monográfico de Letras de Hoje, destinado ao gênero biográfico, agradecer aos autores e às autoras por sua colaboração ao oferecer-nos seus trabalhos, abrindo caminhos para novos desafios tanto teóricos como criativos no campo da biografia. Desejamos a todos leitores, investigadores e interessados em geral - que desfrutem de bons momentos de leitura.

Maria Eunice Moreira Pontifícia Universidade Católica do Rio Grande do Sul (PUCRS), Porto Alegre, Rio Grande do Sul, Brasil

Anna Caballé

Universidad de Barcelona, Barcelona, Espanha

Organizadoras

\section{Referências}

DE MAN, Paul. The rethoric of Romanticism. New York: Columbia University Press, 1984.

LEJEUNE, Philipe. Le pacte autobiographique. Paris: Seuil, 1975.

HAMILTON, Nigel. How to do Biography. Boston: Harvard University Press, 2008. 